IZA DP No. 1187

Aid and Migration: An Analysis of the Impact of Progresa on the Timing and Size of Labour Migration

ManuelaAngelucci

J une 2004 


\title{
Aid and Migration: An Analysis of the Impact of Progresa on the Timing and Size of Labour Migration
}

\author{
Manuela Angelucci \\ University College London, \\ University of Arizona and IZA Bonn \\ Discussion Paper No. 1187 \\ June 2004
}

IZA
P.O. Box 7240
53072 Bonn
Germany

Phone: +49-228-3894-0

Fax: +49-228-3894-180

Email: iza@iza.org

\begin{abstract}
Any opinions expressed here are those of the author(s) and not those of the institute. Research disseminated by IZA may include views on policy, but the institute itself takes no institutional policy positions.
\end{abstract}

The Institute for the Study of Labor (IZA) in Bonn is a local and virtual international research center and a place of communication between science, politics and business. IZA is an independent nonprofit company supported by Deutsche Post World Net. The center is associated with the University of Bonn and offers a stimulating research environment through its research networks, research support, and visitors and doctoral programs. IZA engages in (i) original and internationally competitive research in all fields of labor economics, (ii) development of policy concepts, and (iii) dissemination of research results and concepts to the interested public.

IZA Discussion Papers often represent preliminary work and are circulated to encourage discussion. Citation of such a paper should account for its provisional character. A revised version may be available on the IZA website (www.iza.org) or directly from the author. 


\section{ABSTRACT}

\section{Aid and Migration: An Analysis of the Impact of Progresa on the Timing and Size of Labour Migration*}

This paper models the short and medium-run impact of aid on migration, considering alternatively the effect of unconditional and conditional cash transfers to financially constrained households. Data from the evaluation of a Mexican development program, Progresa, are used to estimate the effect of the potential grant size on migration. The empirical analysis is consistent with model prediction. It shows that the program is associated with an increase in international migration, which is also a positive function of size of potential transfer. The grant may loosen financial constraints. At the same time, fine-tuned conditional grants targeting prospective migrants (in the form of secondary school subsidies) reduce the short-term migration probability. As regards medium-term migration, secondary school beneficiaries are not more likely to migrate than the control group after they complete the subsidised education cycle.

JEL Classification: I38, J18, J16, O15

Keywords: $\quad$ migration, aid, Progresa, Mexico

Manuela Angelucci

Department of Economics

University of Arizona

McClelland Hall 401

PO Box 210108

Tucson, AZ 85721-0108

Email: M.Angelucci@ucl.ac.uk

\footnotetext{
* I am grateful to Gian Luigi Albano, Orazio Attanasio, Marina Capparucci, Costas Meghir and participants to seminars at University College London and University of Rome "La Sapienza" for their constructive and helpful comments. The financial support of the University of Rome "La Sapienza" is gratefully acknowledged. The usual disclaimer applies.
} 


\section{Introduction}

Migration from developing to industrialized countries has been increasing in the last few decades, both in Europe and in America. Efforts are made in developed countries to limit the migrant flow, composed mainly of unskilled labour and in most cases entering the destination country through illegal channels. Individuals migrate when the associated benefits exceed both its direct and opportunity costs. Migration policies in developed countries aim at discouraging unskilled and illegal migration primarily by decreasing its benefits (from employers' sanctions for hiring illegal labour to reduced access to welfare programs for broad categories of illegal and legal aliens) or by increasing its direct cost (through measures ranging from border enforcement to lengthy or costly visa application procedures).

One possible alternative to discourage migration is to increase its opportunity cost by making the prospective migrant better off at home. One mean to achieve such objective is by channelling resources through aid programs. The relationship between aid and migration is complex, though. On the one hand, transfers are expected to improve economic conditions at home, reducing the economic disparity with the destination locations, hence lowering the incentives to leave. On the other hand, if the observed migration level is inferior to the desired one because of financial constraints, subsidies may be used to fund new trips. ${ }^{1}$ Aid programs will affect the likelihood of migrating by changing both income differentials and the possibility of financing trips.

In the last few years a specific type of aid policy has been adopted by a number of Latin American countries. This program, called Progresa in Mexico, is aimed at improving education, health and nutrition of poor rural households. The objective of the current analysis is to understand the relationship between this program and migration, both intraand international. The focus of the analysis is on Mexican migration and it is dictated by data availability. However, the conclusions reached may be easily extended to other sets of countries.

Progresa is an ongoing program that targets poor Mexican rural households (and has been recently extended to urban locations under the name of Oportunidades). Among the various components of the program, there are a (smaller) unconditional nutrition support

\footnotetext{
${ }^{1}$ The relationship between aid and migration for households facing liquidity constraints and having a home bias has been explored, among others, by Faini and Venturini (1993, 1994, 2001). Examples of the use of preference for home consumption to justify return migration may be found in Djajic and Milbourne (1988).
} 
grant, and some (cumulatively larger) schooling subsidies, conditional upon attendance of the last four grades of primary school and first three grades of secondary school. All grants are paid bimonthly, and the schooling subsidy is received upon proof of attendance of at least 85 percent of classes. The size of the transfer grows with the school grade, and is estimated to correspond to two thirds of the wage earned by a teenager in full time employment (Schultz, 2004).

I argue that, although similar in type, primary and secondary school subsidies have different implications in terms of their impact on the recipients' time allocation. Indeed, the subsidy to primary school attendance is roughly equivalent to an unconditional transfer, since primary school enrolment is very high. The secondary school grant conditionality constraint is instead binding for the majority of potential recipients, as secondary school enrolment is much lower. Some eligible schoolchildren are potential migrants. About 33 percent of the observed labour migrations occurring in the sample are undertaken by individuals aged 13 to 19 .

I study the impact that Progresa has on labour migration only, defined as the act of leaving one's hometown to seek employment elsewhere. Progresa enters the decision process of prospective migrants in beneficiary households by changing their opportunity costs, their financial resources and their expected wages.

I group the three monetary components of Progresa into unconditional and conditional transfers. The former refers to the nutrition support and the primary school grant; the latter is the subsidy to secondary education. I show that the two types of grants have different impacts on migration. The unconditional transfer may reduce migration, if individuals have a preference for consumption at home or, more generally, if migration (intangible) costs depend positively on household income. This effect regards the least poor households. At the same time, the unconditional grant may result in higher migration levels because it relaxes financial constraints for the poorest households. The latter fact may have sizeable effects, given that the imperfection of capital markets is one acute problem faced by indigent families in developing countries.

The conditional transfer may reduce migration in the short term by requiring recipients to stay in the home country: prospective migrants may be deterred from migrating, provided that the size of the grant is high enough. Whether beneficiaries revert to migrating at the end of the program depends on skilled wages at home and in the destination locations. In addition, the secondary school subsidy may provide migration incentives to individuals who would have not left home before the program implementation. The 
short-run impact of the two types of transfers on migration are estimated separating the pure income effect from the conditionality one. I distinguish the effect on domestic and international migration.

An interesting feature of the program is that 186 of the 506 sampled villages are randomized out. Eligible residents of these villages are not administered the program until 2000. Eligibility is determined by poverty status, which is defined on the basis of household-specific information collected in the pre-program September 1997 census of Progresa localities. All residents of both control and treatment villages are then interviewed at regular intervals. Detailed data on migration are collected on an annual basis. This provides us with information on households in both control and treatment villages observed both before and during the implementation of the program. I exploit the exogenous variation induced by the randomization to obtain a valid counterfactual for treated households, in order to assess the impact of the various program components on migration.

The empirical analysis confirms that unconditional cash transfers are associated with increased migration, while secondary school grants reduce short-term migration.

The structure of the paper is the following. Section 2 uncovers the relationship between migration and aid, in the form of both unconditional and conditional transfers, by sketching a model of migration and schooling choice. Section 3 describes the data used in the empirical analysis. Section 4 describes the specification used and discusses the identification of the estimable parameters. Section 5 presents the results. Section 6 comments on some policy implications and concludes.

\section{Aid and migration: theoretical considerations}

Mexican migration, especially international one, tends to be temporary in nature, rather than permanent. Household resources are pooled to finance the migration of one or more of its members, normally young males, who leave their family in the community of origin and spend time away, remitting money at regular intervals, or bringing back their savings with them. Remittances are often a sizeable proportion of migrant households' income.

Virtually all children in the sample attend primary school before the program implementation. Hence, since most kids would have attended school even without the transfer, the eligibility constraint is not binding and the subsidy has a pure income effect for the near totality of households.

This is not the case for secondary schoolchildren. While re-enrolment rates are quite 
high for kids with some secondary schooling, the likelihood of beginning high school is low: before the program, less than 40 percent of children aged up to 16 with complete primary school enrol to high school (Attanasio et al., 2002). Three possible factors may explain the low transition rate from primary to secondary education, which are both free in Mexico. One is the higher distance from school, not often available in the village of residence (unlike primary schools, present in most localities). The second one is the higher opportunity cost, as forgone earnings are likely to be higher for teenagers than for younger children. This is especially true given that teenage offsprings are potential migrants. In November 1998, one third of all migrants from poor households in the control group were up to 19 at migration.

Progresa's schooling grant is conditional upon school enrolment and attendance of at least $85 \%$ of classes. Thus, the constraint for transfer eligibility is binding for the majority of households with secondary schoolchildren. Given the differences in pre-program enrolment rates, I consider both income support and primary school grants as unconditional transfers, and the secondary school subsidy as a conditional one.

The effect of a transfer to poor rural households on migration is going to differ according to its eligibility requirements. The effect of an unconditional transfer for these families may be a decline in migration, provided that agents sufficiently dislike moving abroad (which, in turns, may be a function of their wealth). However, the transfer may relax the financial constraint faced by poor households: if families could not reach the desired migration level before the program because of borrowing constraints were coupled with the impossibility to save, they may use the cash subsidies to fund additional trips. Overall, then, the net effect of the unconditional transfer depends on wealth and on access to the credit market, as well as on the "standard" variables from any migration model, and cannot be predicted a priori.

In the case of the conditional school subsidy, if household consumption is sufficiently far from subsistence level, and if the returns to secondary education are high enough, children may move from employment (and migration) to schooling. Grant size for grades 7 to 9 amounts only to approximately two thirds of the wage a child of the corresponding age might earn if working in the village of residence ${ }^{2}$ (Schultz, 2004), however secondary education is expected to provide access to better-paid jobs. The short-term migration reduction might be offset by an increase in the medium run, after secondary school is

\footnotetext{
${ }^{2}$ The size of the transfer rules out the possibility that a child is enrolled in secondary school purely to finance the migration of a family member, if the likelihood of finding a job is very high.
} 
completed. Once the education cycle is completed, the individual will move to the location that pays highest relative wages, net of moving costs.

\subsection{Effect of an unconditional transfer}

The above considerations can be illustrated with the help of a simple model. The effect of an unconditional transfer can be captured in a static framework. Assume there is a continuum of poor households whose utility $(u)$ depends positively on consumption. Households' pooled resources are labeled $Y \geq 0$ (income) and are continuously distributed along their support, with some density function $F(Y)$. Suppose as a starting point that the only source of heterogeneity across households is $Y \geq 0 .{ }^{3}$ Household members include one child who attends one of the subdisied primary school grades and another one who may be eligible for the secondary school grant. There are two locations, "home" and "away". While the younger child attends school and does not work, the elder may choose between working at home $(m=0)$, earning a wage $w^{h}$, and migrating $(m=1)$, where a wage $w^{a}>w^{h}$ is earned. I rule out any form of intra-household bargaining for the allocation of resources or of strategic behaviour by assuming that all members care equally for each other.

Migration has a positive cost. This cost is composed by a monetary element $K$ (such as travel expenses), which is exogenous to the migrant, and by an intangible one, which is a positive function of potential home consumption. Assume for simplicity that intangible migration costs equal $\left(Y+w^{h}\right) / \alpha$, with $\alpha>1$. The wealthier the household, the larger is the intangible cost of not being together. This can be thought of as individuals suffering from being (or consuming) apart (as supposed in the previous chapter). 1/ $\alpha$ measures the comparative dislike for "away" consumption, or for not consuming together at home. The smaller the fraction, hence the larger $\alpha$, the smaller is the disutility from consuming away from home. When $\alpha \rightarrow \infty$, household members are indifferent between the location where consumption occurs, and care only about its maximization. ${ }^{4}$

I represent financial constraints by ruling out saving and borrowing. All income earned is consumed in the current period. I further assume that the migration cost is borne upfront, at the beginning of the period. Hence, only households with sufficiently high income $(Y \geq K)$ are able to finance the migration, since there cannot be negative consumption. I

\footnotetext{
${ }^{3}$ This assumption is not required in the empirical analysis

${ }^{4}$ The latter is a broad version of the standard opportunity cost argument, including all types of goods that cannot be enjoyed while abroad.
} 
also assume for simplicity that utility is a linear function of the parameters of the model.

The maximization problem is

$$
\max _{m=\{0,1\}} u=Y+(1-m) w^{h}+m\left(w^{a}-K-\left(Y+w^{h}\right) / \alpha\right)
$$

All households may potentially benefit from the migration, but only those with income such that $Y \geq K$ and $Y<\left(w^{a}-w^{h}-K\right) \alpha-w^{h}$ will undertake it. Very poor families (with income $Y<K)$ are unable to finance the trip, while the least poor ones $(Y>$ $\left.\left(w^{a}-w^{h}-K\right) \alpha-w^{h}\right)$ have too high an intangible cost. They are already sufficiently wealthy that the higher income associated with the migration is offset by the cost of being apart.

An unconditional transfer $(T)$ in the form of a nutrition support or a primary school subsidy has a twofold effect. It increases household income, relaxing the financial constraint of some of the families for whom migration was precluded in the baseline case. Hence, some households who were previously credit constrained will be able to pay for the migration. These are families with income $Y \in[K-T ; K)$. At the same time, the transfer increases migration costs, $K+\frac{\left(Y+w^{h}\right)}{\alpha}<K+\frac{\left(Y+w^{h}\right)+T}{\alpha}$. Households with incomes close to the upper threshold will stop migrating. This holds for families with income $Y \in\left[\left(w^{a}-w^{h}-K\right) \alpha-w^{h}-T ;\left(w^{a}-w^{h}-K\right) \alpha-w^{h}\right)$.

The overall effect is ambiguous and depends on $F(Y)$. However, the more stringent the financial constraint and the poorer the households, the higher the likelihood that there will be a net increase in migration. ${ }^{5} 6$

\subsection{Effect of a conditional transfer}

I now proceed to illustrate the effect of a secondary school subsidy. The nature of this problem is dynamic, because current education is associated with higher future earnings. I capture the dynamic effects by adding a second period to the model and by modelling explicitly the schooling choice of the adolescent son. This choice is discrete $(s=0,1)$, hence school can be attended for the whole period only and is not compatible with migration.

\footnotetext{
${ }^{5}$ In the absence of intangible migration costs linked positively to income, the effect of the unconditional transfer is an unambiguous increase in migration.

${ }^{6}$ Modelling temporary migration by letting individuals leave for a fraction of the period (i.e. $m \in[0,1]$ ) yields the same ambiguous impact of unconditional transfer on migration flow, while it reduces migration duration.
} 
School attendance has a positive price, $p$, which represents both its direct (e.g. travel expenses) and its opportunity cost (forgone earnings). Given the borrowing constraints, only households whose income exceeds education $\operatorname{costs}(Y>p)$ are able to finance education. Each pupil is exogenously endowed with the ability to transform schooling into particular types of skills, which are rewarded differently at home and away. Hence, each student in the second period has pairs of home and away-specific human capital, $k=\left(k^{h}, k^{a}\right)^{\prime}$, which will determine wages in both locations $\left(w^{h}(k)\right.$ and $\left.w^{a}(k)\right)$. Schooling is associated with skilled wages, $w^{j}(k)>w^{j}$, for $j=h, a$ and for all $k$. Wages are identical in the two periods for individuals with no secondary education. Education changes the incentives to migrate by increasing next period home and away wages and by raising the intangible cost of migration (through the higher home wage). The intensity of these effects is a function of individual-specific returns to education, and the decisions will vary depending on households' income levels.

The maximization problem becomes

$$
\begin{aligned}
& \max _{m=\{0,1\}, s=\{0,1\}} u_{1}+u_{2} \\
u_{1}= & Y+\left(1-m_{1}\right)\left(w^{h}-p s\right)+m_{1}\left(w^{a}-K-\left(Y+w^{h}\right) / \alpha\right) \\
u_{2}= & Y+\left(1-m_{2}\right) w^{h}(k)+m_{2}\left[w^{a}(k)-\left(K-\left(Y+w^{h}\left(k_{1\{s=1\}}\right)\right) / \alpha\right)_{1}\left\{m_{1}=0\right\}\right.
\end{aligned}
$$

There are six potential outcomes, depending on whether one migrates or not in either period and on the schooling choice in period one. The associated utility is represented by the triplets $\left(m_{1}, m_{2}, s\right)$, where each parameter can take two different values ( 0 or 1$)$. Hence, a household where the teenage son goes to school in the first period and migrates in the second one has a utility of $(0,1,1)$. Different outcomes are chosen according to family income and returns to education at "home" and "away". These are summarized in Table 1, and discussed below.

Table 1: Inter-temporal schooling and migration decisions

\begin{tabular}{lllll}
\hline \hline & $Y<p$ & $Y \in(p, K)$ & $Y \in(K, \bar{Y})$ & $Y>\bar{Y}$ \\
\hline Low $k$ & $(0,0,0)$ & $(0,0,0)$ & $(1,1,0)$ & $(0,0,0)$ \\
High enough $k^{h}$ & $(0,0,0)$ & $(0,0,1)$ & $(0,0,1)$ & $(0,0,1)$ \\
High enough $k^{a}$ & $(0,0,0)$ & $(0,0,0)$ & $(0,1,1)$ & $(0,0,0)$ \\
\hline \hline
\end{tabular}


The poorest families with $Y<p$ will neither have their teenage child migrate nor go to school. Those with income $Y \in(p, K)$ will choose whether to continue education depending on the level of skilled home wages. Consider a deterministic world where individuals know their human capital production function. Agents will go to school if the following disequality holds: $w^{j}(k)-w^{h}>p$ for $j=h, a$ if $Y \geq K$ and for $j=h$ if $Y<K$. It follows that for households with income $Y \in(p, K),(0,0,1)>(0,0,0)$ for sufficiently high $k^{h}$.

Since $w^{a}>w^{h}$, agents who choose not to purchase education will migrate in both periods, provided that they are not financially constrained. This occurs because once the migration cost has been borne, consumption is maximized by staying away for as long as possible. This implies that $(1,1,0)>(1,0,0)$ and $(1,1,0)>(0,1,0)$. Hence, migrants who are not financially constrained will choose one of the three outcomes: $(1,1,0),(0,1,1)$ or $(0,0,1)$ according to their location-specific human capital. For instance, outcome $(1,1,0)$ will be chosen by households with pairs of human capital $k$ and income $Y$ such that

$$
2 w^{a}-K-\left(Y+w^{h}\right) / \alpha>w^{h}(k)-w^{h}-p
$$

i.e. $(1,1,0)>(0,0,1)$, and

$$
2 w^{a}>w^{a}(k)+w^{h}(\alpha+1) / \alpha-w^{h}(k) / \alpha-p
$$

i.e. $(1,1,0)>(0,1,1)$.

Three classes of individuals do not migrate in either period. Those with very low income, $Y<K$; those with high enough $k^{h}$ to make "home" skilled wages preferable to migrating in one or two periods; the wealthiest households. This latter group is composed by families with income $Y>\bar{Y}$, where

$$
\bar{Y}=\left[w^{a}(k)-p-w^{h}-K\right] \alpha-w^{h}(k) / \alpha
$$

for individuals with high $k^{a}$ (whose alternative is to go to school in order to access the "away" skilled wage $\left.w^{a}(k)\right)$ and

$$
\bar{Y}=\left[2\left(w^{a}-w^{h}\right)-K\right] \alpha-w^{h} / \alpha
$$

for those with low $k$ (whose second best is to migrate in both periods).

The education subsidy reduces the price of education by an amount $\Delta p$. The general effect of the subsidy of course is to increase attendance of secondary education. Regarding 
its effect on migration, the schooling subsidy unambiguously reduces short-term migration. This happens because the lower cost of education induces some individuals to move from a two-period migration to education. Thus, the subsidy is associated with a reduction in the number of $(1,1,0)$ choices in favour of $(0,0,1)$ and $(0,1,1)$ outcomes.

The subsidy's medium-term effect on migration is instead uncertain. In fact, individuals with sufficiently high "home" return to education will not leave in the second period, i.e. they will switch from $(1,1,0)$ to $(0,0,1)$, as shown by (1). Agents with a large enough "away" skilled wage will instead go to school in the first period in order to migrate in the following one and to access "away" skilled wages, moving from $(1,1,0)$ to $(0,1,1)$, as illustrated in (2). In addition, the lower price of education will induce children in some of the least poor families (the ones with high "away" returns to education) to attend secondary school in order to migrate in the second period, moving from $(0,0,0)$ to $(0,1,1)$, as noticeable from (3).

Although the net effect of the secondary school grant on medium-term migration is not clear, it is possible to make some general considerations to understand its potential overall effect. Given that the program targets poor rural households, it is expected that "home" returns to higher education are not as high as "away" ones. It is probable that individuals who switched from migration to education in the first period will then leave the village in the second one. However, multiple migration destination are possible, depending on comparative net benefits from a domestic migration to urban areas and an international one. The comparative advantage of an international versus a domestic migration is lower for educated than uneducated migrants, if individuals can only enter the U.S. illegally, since it is likely that wages in the secondary segment of the U.S. labour market are less sensitive to changes in migrants' education level. Considering in addition the higher migration cost, it is not certain whether migrants with secondary schooling will migrate abroad or remain in Mexico.

In short, the effect of Progresa on migration cannot be inferred with certainty. This is due to various facts. First, the program's different components may provide opposite incentives to migrate. Second, the same type of subsidy may affect household's migration level differently according to their degree of poverty, of credit constraints and their children's comparative skilled wages at "home" and "away". Third, the effect of the conditional component of the program may vary in the short and in the medium run.

Modelling the effect of Progresa on migration has highlighted the following points. The unconditional grant links current migration to poverty by an inverse u-shaped function: 
it increases emigration of some poor households by relaxing their credit constraints, while reducing the incentives to leave of the least indigent recipients. Given the poverty level of program recipient, though, one expects that the loosening of financial constraint associated with the program recipience dominates the higher intangible migration costs, resulting in a net migration increase. Contemporaneous migration appears to be a negative function of the conditional grant, instead, as both the high school subsidy and the future access to skilled wages provide incentives to stay at home. Hence, I expect the conditional and the unconditional program components to have opposite effects on the likelihood of migrating.

The volume of future migration depends positively on "away" skilled wages and negatively on the "home" one. If the latter is sufficiently high, some individuals will refrain from migrating also in the second period. However, given the comparative scarcity in skilled labour demand in rural areas, one may expect migration to increase in the second period. Whether individuals will migrate to Mexican urban areas, or will prefer to go to the United States depends on the comparative net benefits, which are functions of wages and costs, which in turn depend on the type of international migration (legal or undocumented). ${ }^{7}$

The estimation of the observed net impact and the effect of the program's various components is the subject of the next sections.

\section{The Progresa data}

Progresa targets Mexican poor rural households and provides grants to improve education, health, consumption and the role of women in the household. Its main monetary component, apart from a smaller nutritional subsidy, is in the form of a schooling subsidy to children attending the last third grades of primary school and the three grades of secondary school. Transfers are made to women only (normally the spouse of the household head), and are conditional upon regular visits to health centres, to "platicas" where women are taught about health and nutrition issues, and to a school attendance rate of at least $85 \%$ of term time. An interesting feature of the program is that, in order to permit the

\footnotetext{
${ }^{7}$ Progresa is likely to influence migration through two further channels: changes in income distribution and risk. Transfers to poor households reduce both their relative deprivation (i.e. their rank in the community income distribution) and income variation. Since migration is a mean to smooth risk and improve one's relative, as well as absolute income, then Progresa will result in an unambiguous migration reduction through these channels.
} 
evaluation of its impact, 186 of the 506 villages sampled for evaluation purposes are randomized out. Poor residents of these villages are not administered the program until 2000. Households are classified into poor and non-poor according to the information collected in the pre-program September 1997 census of Progresa localities. All residents of both control and treatment villages are then interviewed at biannual intervals. Detailed data are collected on health, consumption, income and employment, education and migration at least in one of the two annual surveys. ${ }^{8}$

Progresa has a dual round of selection of eligible households. 52 percent of households are initially classified as poor in 1997. The following year, a further group of households initially classified as non-poor were later included in the beneficiary group. However, most of this latter set of families did not receive the transfers for exogenous reasons, irrespective of their compliance with the eligibility rules. Because of this reason, I restrict the valid sample to the sole households classified as poor in $1997 . .^{9}$

I consider labour migration only. Both the 1998 and the 1999 surveys (unlike the 1997 one) record the motivations for leaving one's household of origin, identifying people who leave the household to work, to study and to get married. I distinguish between domestic and international migration. I will refer alternatively to international or U.S. migration, since this is the most likely destination for international migrants.

95 percent of all trips occur when the individual is aged between 14 and 40. Thus, I consider the sole subset of people within this age interval as potential migrants. Older and younger individuals are discarded from the analysis. As a result, entire households are dropped from the valid sample, which is composed of approximately 27,000 individuals from 10,000 households. About 17,000 individuals (7,000 households) belong to the treatment group, as shown in Table 2.

The treatment group in 1998 and 1999 is split according to transfer recipience: $B$ stands for actual beneficiaries, while $F$ and $N C$ indicate forgotten and non-complier subjects, respectively. Only 6 families in 1998 are not administered the subsidies, although entitled to, irrespective of compliance with program requirements. The number of non-compliers is larger, but still quite small when compared to the size of the treatment group. Indeed,

\footnotetext{
${ }^{8}$ Information on migration is collected in the September 1997, October/November 1998 and November 1999 waves, i.e. rounds 1,3 and 5 of the survey.

${ }^{9}$ It would be possible to estimate the effect of Progresa on the migration rate of the omitted groups. However, such approach is not pursued here because of the small sample sizes of the relevant group and the very few observed migrations
} 
Table 2: Sample size of sub-groups

\begin{tabular}{|c|c|c|c|c|c|c|c|}
\hline & 1997 & \multicolumn{3}{|c|}{1998} & \multicolumn{3}{|c|}{1999} \\
\hline & All & B & $\mathrm{F}$ & $\mathrm{NC}$ & B & $\mathrm{F}$ & $\mathrm{NC}$ \\
\hline Treatment & & & & & & & \\
\hline Individuals & 16,877 & 16,532 & 27 & 594 & 15,590 & 25 & 464 \\
\hline Households & 7192 & 6617 & 6 & 260 & 6136 & 5 & 194 \\
\hline Control & & \multirow{2}{*}{\multicolumn{3}{|c|}{10,295}} & \multirow{2}{*}{\multicolumn{3}{|c|}{10,029}} \\
\hline Individuals & 10,278 & & & & & & \\
\hline Households & 4314 & \multicolumn{3}{|c|}{4096} & \multicolumn{3}{|c|}{3909} \\
\hline
\end{tabular}

the sum of the two groups who do not receive the transfers among 1997 poor amounts to around 3 percent of total potential beneficiaries in the post-program years.

\section{Econometric analysis}

The small size of non-compliers and the absence of pre-program significant differences in average migration rates between control and treatment group simplify the econometric analysis greatly. The major advantage of the randomization is that control and treatment group do not differ in terms of unobservable characteristics. Hence cross-sectional analyses can provide consistent estimates of average program effects. Although group means provide unbiased estimates of the program effect, regression analysis may be performed to increase the estimate precision and to control for relevant variables (such as the presence of shocks, which may not occur randomly in case of natural disasters occurring in specific geographic areas).

\subsection{Estimable parameters}

Two parameters commonly estimated in the program evaluation literature are intention to treat and average treatment on the treated effects (TTEs). The former is estimated by comparing all eligible individuals in the treatment and control groups. This parameter can be interpreted as measuring the average program effect for all eligible households irrespective of actual treatment.

$$
E[m \mid T=1]-E[m \mid T=0]
$$


$T=\{0,1\}$ for subjects in control and treatment villages, respectively. $m$ is some measure of migration to be discussed later.

$T T E$ measures the average impact of the program on actual beneficiaries. Since noncompliers are quite scarce in the considered group, amounting to approximately 3 percent of the sample, I expect the difference between treatment availability and use to be negligible. $^{10}$

$$
\begin{aligned}
E[m \mid T= & 1]-E[m \mid T=0] \\
= & 0.97\{E[m \mid T=1, B=1]-E[m \mid T=0, B=1]\} \\
& +0.03\{E[m \mid T=1, B=0]-E[m \mid T=0, B=0]\} \\
\cong & E[m \mid T=1, B=1]-E[m \mid T=0, B=1]
\end{aligned}
$$

$B$ refers to being a program dropout, or actual beneficiary, $(=1)$ or not $(=0)$. In the remaining sections I will only refer to TTEs, although the parameters that I am actually estimating are the intention to treat ones.

The actual grant received by beneficiaries is not observed. Not all eligible children may end up going to school. Thus, I will use potential grant size and composition when estimating the effects of the program components. Nevertheless, the resulting parameters have a clear policy significance, since they measure the impact of what is under the control of the policy maker, rather than parameters depending on households' acceptance of the treatment.

\subsection{Program effect: specification and identification}

The identification of average TTEs relies on the village randomization and is based upon the claim that eligible individuals do not differ from control ones in terms of unobservable characteristics. Thus, unbiased counterfactuals of the above parameters are given by their sample analogs $\left(\bar{m}_{T}, T=0,1\right)$. The simplest way, and natural starting point, is to compute simple group means and test for their statistical difference.

$$
E[m \mid T=1]-E[m \mid T=0]=\bar{m}_{1}-\bar{m}_{0}
$$

In the case of a dichotomous variable these are the difference in average likelihood of migrating due to Progresa. I adopt this approach to estimate the overall program effect

\footnotetext{
${ }^{10}$ The results from the empirical analysis do not change if these two groups are omitted.
} 
on migration, alternatively pooling migrations and distinguishing between domestic and international ones. ${ }^{11}$

The theoretical model highlights how the conditional and unconditional components of the transfer may impact migration differently, hence how a grant of a given size may affect households in varying ways, depending on beneficiaries' and households' characteristics. A simple way to test these hypotheses is to condition on potential grant size and composition. I create a variable that measures the potential size of the grant to which households would be entitled, were all their children to attend school. Potential grant size varies between 190 and 230 pesos and is capped to a maximum of 1250 and 1500 pesos (in November 1998 and 1999, respectively). The increases in grant levels are such that the value of the subsidy is constant over time. I also compute the proportion of potential grant associated with eligible males' secondary school attendance. I consider males only because they are more likely to be migrants than females in the same age group. ${ }^{12}$ At most $83 \%$ of total potential grant may come from male secondary scholarships because of the income support provided to all eligible families. ${ }^{13}$

I group subjects according to the household grant size $(g)$ and composition $(p) . g$ takes two values: 0 for low grant sizes, up to its mean, and 1 for larger than average transfers. $p$ has three levels: 0 , for households with all unconditional grant; 1 , for up to $50 \%$ conditional grant, which is the median for households with secondary male schoolchildren (the mean is $51 \%$ ); 2, for more than $50 \%$ conditional grant. I first test whether there are significant differences in the migration propensity of treatment and control households grouping them

\footnotetext{
${ }^{11}$ The pre-program information cannot be used to obtain difference in difference estimates because the motives for leaving one's household are not indicated in 1997. Indeed, suppose that the "true" effect of Progresa is a surge in labour migration and a decrease in other types of migration (to study, to get married). The different effects may offset each other. This may explain the difference in the current results and those by Steckov textitet al. (2003), who find that Progresa reduces international migration.

${ }^{12}$ However, for robustness checks I perform the empirical analysis considering also grant composition in terms of female secondary school subsidy. The latter does not appear to be related to migration as much as the former.

${ }^{13}$ Further details regarding the creation of these variables, the presence of a common support among control and treatment households and the amount of variation within the two variables are provided in the Appendix.
} 
by grant size and composition. In other words, I estimate the following effects:

$$
\begin{aligned}
T T E_{g k} & =E[m \mid T=1, g=k]-E[m \mid T=0, g=k] \\
T T E_{p j} & =E[m \mid T=1, p=j]-E[m \mid T=0, p=j] \\
k & =0,1 \quad j=0,1,2
\end{aligned}
$$

There are five such effects. Define $m_{i}^{*}$ the dependent variable of the latent regression model that determines the migration choice according to the following equality: $\operatorname{Pr}\left(m_{i}=\right.$ $1)=\operatorname{Pr}\left(m_{i}^{*}>0\right)$, where $m_{i}$ indicates whether the migration is undertaken or not. In the case of discrete $g$ and $p$ :

$$
m_{i}^{*}=\alpha_{0}+\alpha_{1} T_{i}+\alpha_{2} g_{i}+\sum_{j} \alpha_{3 j} p_{i j}+\alpha_{4} g_{i} T_{i}+\gamma X_{i}+u_{i} \quad j=1,2
$$

$X$ represents additional control variables. $u$ is some white-noise error following some fully-specified parametric distribution. The subscript $i$ indicates the $i$-th individual, $i=$ $1, . ., N$. When $g=0$ and $T=0$ are the omitted groups and the regression is estimated by linear probability model ${ }^{14}, T T E_{g 1}=\alpha_{1}+\alpha_{4}$ and $T T E_{g 0}=\alpha_{1}$. Inverting $g$ and $p$ provides estimates of the TTEs for the composition effects. These parameters permit to compare different groups of households, but they do not permit to understand whether any difference in migration propensity is attributable to size or conditionality effects.

To disentangle the two effects, I then proceed to estimate the impact of each component, conditioning on the other one, i.e. interacting both by the treatment dummy. Thus, I measure the income effect testing whether, conditioning on grant composition, the effect of the grant on migration is larger for larger grant sizes. For instance, suppose that households face severe financial constraints, and use the grants to fund additional migrations. After conditioning on grant composition and other variables that capture the overall migration propensity in the family, it is expected that migrants with more funds will be more likely to migrate than those with little money transferred to. In other words, one expects the following equation to be positive.

$$
\begin{aligned}
& \{E[m \mid T=1, g=1]-E[m \mid T=0, g=1]\} \\
& -\{E[m \mid T=1, g=0]-E[m \mid T=0, g=0]\} \\
= & T T E_{g 10}=T T E_{g 1}-T T E_{g 0}
\end{aligned}
$$

\footnotetext{
${ }^{14}$ For nonlinear models, the coefficient has to be multiplied by the value of the $c d f$ at the specific variable levels.
} 
The same applies to the composition effects, hence the labels $T T E_{p j l}$, with $j, l=0,1,2$ and $j \neq l$. The subscripts $j$ and $l$ refer to the three possible pairwise comparisons of the conditional grant proportions ( $p=$ zero, low and high, as explained above). In the case of discrete $g$ and $p$ :

$$
m_{i}^{*}=\beta_{1} T_{i}+\beta_{2} g_{i}+\sum_{j} \beta_{3 j} p_{i j}+\beta_{4} g_{i} T_{i}+\sum_{j} \beta_{5 j} p_{i j} T_{i}+\gamma X_{i}+u_{i} \quad j=1,2
$$

The coefficient on interacted grant size from (8), $\beta_{4}$, provides an unbiased estimates of (7). The coefficients $\beta_{5 j}$ capture the impact of program conditionality on migration: $\beta_{51}<0$ and $\beta_{52}<0$ support the view that, given grant size, migration is lower among household where the program requirements are binding.

In all regressions, I add a set of conditioning variables that are expected to capture different migration propensities of households with different demographic composition (a detailed explanation follows in the result section). Furthermore, I estimate (8) conditioning on continuous $g$ and $p$, assumed alternatively to be linear and quadratic. In this case, the above coefficients are measuring the change in migration propensity caused by a marginal increase in the money received (in the case of $g$ ) or in the proportion of the grant due to male secondary scholarships. Identification in this case hinges on the explicit functional form assumptions.

The magnitude of the grant's income effect depends on its relative size, when compared with average migration costs. Average monthly grant size for families with children is 348 pesos $^{15}$, and 250 pesos for childless households, while the male secondary school subsidy varies between 200 and 250 pesos in 1998 and 1999. I expect costs to vary with distance from the chosen locality, and to be highest for international migrations also for an additional reason: the vast majority of international migrations are illegal and tend to hire smugglers to cross the border (77 percent of illegal migrants resorted to hiring a smuggler in the 1980s and 1990s, paying on average 5401990 dollars for the years 1993-1998). Given these high U.S. migration costs, it is unlikely that the cumulative grant in November 1998 is sufficient to finance an international trip.

The program may provide incentives to return from a migration. Looking at average remittances, the direct financial incentives appear to be low for U.S. migrants, but sizeable for domestic ones. International and domestic migrants remit on average 80 and 400 pesos per month, respectively, and households with migrants have on average 1.5 mem-

\footnotetext{
${ }^{15}$ One dollar was roughly 10 pesos in 1998 and 1999.
} 
bers away. ${ }^{16}$ No direct information is available on return migrants in the 1998 and 1999 waves. However, data on migrants' stocks are collected. I order to obtain an estimate of the program impact on migration net flows I compare the stocks of labour migrants in the treatment and control groups. Given the absence of pre-program mean difference in migration levels between control and treatment households, any difference in stock can be attributed to differences in net flows:

$$
\begin{aligned}
S_{98}^{T}-S_{98}^{C} & =S_{97}^{T}-S_{97}^{C}+N F_{98}^{T}-N F_{98}^{C}=N F_{98}^{T}-N F_{98}^{C} \\
\text { if } \quad S_{97}^{T} & =S_{97}^{C}
\end{aligned}
$$

where $S$ and $N F$ indicate migrant stock and net flow, the subscripts refer to the relevant year and the superscripts to treatment and control group. When comparing migrant stocks in 1999, I am looking at the difference in net flows in the two years after the pre-program data are collected.

\subsection{Does the randomization work? Pre-program means}

The identification of the parameters of interest is based on cross-sectional variation. Thus, it relies on the validity of the randomization, meaning that there are no unobservable differences in migration patterns among treatment and control groups. ${ }^{17}$ One possible way to insure that time-invariant unobservable individual effects are not driving the result may be to perform some difference-in-difference analysis. However, labour migrations are not identified in the 1997 data. All household members who are away at the time the interview is carried are classified as migrants, including those who left to get married and to go to study. While Progresa is expected to increase labour migration, the other types of migrants may decrease, given the higher incentives to stay in treated villages. If the two effects offset each other, the program may not appear to affect labour migration, even though it might actually do.

Alternatively, one can test for pre-program different migration levels. Given the interest in the effect of the grant for different household composition, one has to control whether there are significant differences in pre-program migration levels for families with

\footnotetext{
${ }^{16}$ Average Progresa subsidy size data are from Albarran and Attanasio (2001), information on smuggler hiring and associated cost has been computed from data collected by the Mexican Migration Project. Migrant number and monthly remittances have been computed from the November 1998 Encel survey, using average values for the control group.

${ }^{17}$ This assumption is especially crucial in light of the few migrations occurring in the sample.
} 
different number and type of schoolchildren. Extensive evidence will be provided of the absence of significant differences in the migration rates of various sets of households in the treatment and control groups.

I classify migration according to its location, computing three different variables (total migration, domestic and international one). For each of these variables, I consider: average individual migration, proportion of families with at least one migrant and average household migration (for households with a positive number of migrants).

Table 3: Pre-program mean migration levels

\begin{tabular}{|c|c|c|c|c|}
\hline & & \multicolumn{3}{|c|}{ Valid 1997 observations } \\
\hline & & All & US mig & MX mig \\
\hline \multirow{6}{*}{ Treatment } & \multirow[t]{2}{*}{ Individuals } & .0174 & .0071 & .0103 \\
\hline & & $(.0019)$ & $(.0012)$ & $(.0014)$ \\
\hline & \multirow[t]{2}{*}{ Households ( $\%$ mig $>0)$} & .0129 & .0055 & .0076 \\
\hline & & $(.0016)$ & $(.0010)$ & $(.0012)$ \\
\hline & \multirow[t]{2}{*}{ Households (mean) ${ }^{a}$} & 1.505 & 1.475 & 1.472 \\
\hline & & $(.0730)$ & $(.1299)$ & $(.0848)$ \\
\hline \multirow{6}{*}{ Control } & \multirow[t]{2}{*}{ Individuals } & .0149 & .0053 & .0095 \\
\hline & & $(.0025)$ & $(.0011)$ & $(.0023)$ \\
\hline & \multirow[t]{2}{*}{ Households $(\% \mathrm{mig}>0$ ) } & .0118 & .0044 & .0076 \\
\hline & & $(.0019)$ & $(.0011)$ & $(.0015)$ \\
\hline & \multirow[t]{2}{*}{ Households (mean) ${ }^{a}$} & 1.588 & 1.650 & 1.484 \\
\hline & & $(.1424)$ & $(.1596)$ & $(.1902)$ \\
\hline
\end{tabular}

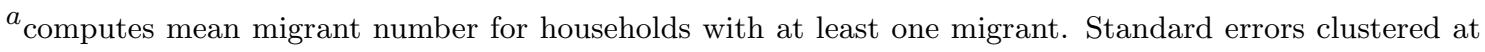
the village level.

Average pre-program migration rates along these three dimensions are presented in Table 3. No significant differences are detected between treatment and control subjects. As migration motives are not known in 1997, the values below include not only labour migrations, but also trips for educational purposes (very few ones) and to get married.

Although true labour migration rates are inflated, the number of individuals who leave the household in 1997 is extremely low. Fewer than one percent of the sampled individuals are foreign migrants, the proportion rising only slightly for domestic migration. The low migration rate is consistent with the financial constraint hypothesis: some profitable migrations may not have been funded because of the impossibility to borrow. 
Table 4: Pre-program migration differences for various percentiles, $\mathrm{p}$ values

\begin{tabular}{lcccc}
\hline \hline & \multicolumn{2}{c}{ Grant size } & \multicolumn{2}{c}{ Composition $^{a}$} \\
\hline p-value of difference & migUS & migMX & migUS & migMX \\
\hline 25-th percentile & 0.678 & 0.499 & 0.263 & 0.886 \\
50-th percentile & 0.160 & 0.719 & 0.263 & 0.886 \\
75-th percentile & 0.291 & 0.473 & 0.263 & 0.886 \\
90-th percentile & 0.229 & 0.813 & 0.355 & 0.345 \\
\hline \hline
\end{tabular}

${ }^{a}$ : grant composition measured as proportion of grant due to male secondary school attendance. Standard errors clustered at the village level.

The computation of TTEs for several sub-groups of individuals and the interaction with family demographic characteristics (as measured by proportion of grant due to secondary school grant for males) means that one needs to test whether the pre-program distribution of migration differs among control and treatment villages. Mean equality in this case is not a sufficient condition. I test for difference migration rates for households at the 25th, 50-th, 75-th and 90-th percentile of both potential grant size and grant composition measures. The results, which are reported in Table 4, show that there are no significant differences in pre-program migration rates. I report results at the individual level only, since they convey the same message as the household-level ones.

To further test for the absence of significant differences in pre-program migration levels, I regress (6) computing the pre-program equivalent of $T T E_{g s}$ and $T T E_{p s}$ using 1997 data. All parameters but one are not statistically different from zero.

Table 5 reveals that households with a high proportion of secondary school children (4\% of the total 1997 sample) are significantly more likely to have foreign migrant members if they are based in Progresa villages. This corresponds to two families among the group of 334 households in treatment villages having foreign migrants, while no household among the 161 control ones has international migrants. Hence, the significant difference may be due to the small size of the cells and to the very few international trips within cell. In the remaining part of the analysis, particular care will be taken in comparing migration rates for groups that are potentially different in 1997. Finally, I estimate (8) using 1997 data: the coefficients $\beta_{4}$ and $\beta_{5 j}$ are never statistically different from zero. ${ }^{18}$

\footnotetext{
${ }^{18}$ Results not shown but available upon request.
} 
Table 5: Pre-program migration difference for various household types

\begin{tabular}{lcccccc}
\hline \hline & \multicolumn{3}{c}{ Individual } & \multicolumn{3}{c}{ Household } \\
& migUS & migMX & migALL & migUS & migMX & migALL \\
\hline $\mathrm{TTE}_{g 0}$ & .0006 & .0009 & .0015 & .0005 & .0011 & .0017 \\
& $.0015)$ & $(.0023)$ & $(.0030)$ & $(.0011)$ & $(.0015)$ & $(.0021)$ \\
$\mathrm{TTE}_{g 1}$ & .0024 & -.0002 & .0024 & .0011 & .0002 & .0009 \\
& $.0017)$ & $(.0021)$ & $(.0027)$ & $(.0015)$ & $(.0019)$ & $(.0028)$ \\
$\mathrm{TTE}_{p 0}$ & .0015 & .0000 & .0016 & .0006 & .0005 & .0012 \\
& $.0013)$ & $(.0020)$ & $(.0026)$ & $(.0009)$ & $(.0014)$ & $(.0020)$ \\
$\mathrm{TTE}_{p 1}$ & .0003 & .0016 & .0025 & -.0003 & .0023 & .0009 \\
& $.0031)$ & $(.0039)$ & $(.0049)$ & $(.0023)$ & $(.0037)$ & $(.0052)$ \\
$\mathrm{TTE}_{p 2}$ & -.0003 & .0050 & .0055 & $.0903^{* * *}$ & .0038 & .0080 \\
& $. .0051)$ & $(.0050)$ & $(.0075)$ & $(.0317)$ & $(.0041)$ & $(.0071)$ \\
\hline \hline
\end{tabular}

Standard errors clustered at the village level.

\section{$5 \quad$ Aid and migration: results}

This section presents estimates of the program impact on various migration measures, both at the individual and at the household level. The advantage of using individual-level data is that the larger sample size increases the precision of the estimates. Its potential drawback is that it may not truly represent the decision-making process, because number and type of migrants may be chosen simultaneously at the household level. Thus, I also estimate the impact of the program components on migration using families as the unit of analysis. I look at the program effect on the likelihood of having at least one migrant in the household using a probit model. I estimate the individual likelihood of being a domestic or international migrant by multinomial logit, the ones at the household level by bivariate probit, and the likelihood of being a migrant irrespective of the destination by probit for both individual- and household-level data.

In order to improve the precision of the estimates, I add the following set of conditioning variables to all regressions. Number of household members aged 14 to 40; size of owned land; dummies for whether household suffered from a series of "shocks" during the interview year; age of household head (or spouse, in case of missing information). This first set of regressors is added to both individual- and household-level regressions. Age (as second-order polynomial), gender and number of domestic and international migrants 
(excluding self) are added to individual-level specifications only. I also experimented with additional regressors, such as presence of disabled individuals; individual temporary migration experience; village migration intensity; type and number of animals owned; federal state dummies. Including these variables does not change the results and has no sizeable effect on the standard errors. All household-specific variables are from the 1997 survey, excluding shocks.

Robust standard errors are clustered at the village level, since localities are the primary sampling units and the randomization is performed at the village level.

\subsection{Average program effect on migration}

Table 6: 1998 and 1999 average migration levels

\begin{tabular}{|c|c|c|c|c|c|c|}
\hline & \multicolumn{3}{|c|}{ "Valid 1998 observations } & \multicolumn{3}{|c|}{ "Valid 1999 observations } \\
\hline & All & US mig & MX mig & All & US mig & MX mig \\
\hline \multicolumn{7}{|l|}{ Treatment } \\
\hline Individuals & .0455 & $.0112^{*}$ & .0342 & .0317 & 0.0078 & .0230 \\
\hline Households ( $\%$ mig $>0)$ & .0324 & $.0141^{*}$ & .0192 & .0322 & $.0150^{*}$ & .0187 \\
\hline Households (mean) & 1.487 & 1.407 & 1.471 & 1.465 & 1.353 & 1.459 \\
\hline \multicolumn{7}{|l|}{ Control } \\
\hline Individuals & .0464 & $.0070^{*}$ & .0393 & .0360 & .0097 & .0264 \\
\hline Households ( $\%$ mig $>0)$ & .0239 & $.0088^{*}$ & .0153 & .0260 & $.0087^{*}$ & .0188 \\
\hline Households (mean) & 1.504 & 1.552 & 1.454 & 1.383 & 1.486 & 1.291 \\
\hline P-value of mean difference ${ }^{a}$ & 0.878 & $0.065^{*}$ & 0.338 & 0.283 & 0.703 & 0.258 \\
\hline P-value of mean difference ${ }^{b}$ & 0.107 & $0.100^{*}$ & 0.364 & 0.268 & $0.070^{*}$ & 0.989 \\
\hline$P$-value of mean difference ${ }^{c}$ & 0.884 & 0.389 & 0.920 & 0.420 & 0.441 & 0.151 \\
\hline
\end{tabular}

computes mean migrant number for household with at least one migrant.

${ }^{a}$ p-value of the mean difference at the individual level.

${ }^{b, c}$ p-value of the mean difference at the household level $b=$ proportion; $c=$ mean).

Table 6 provides group means of the three measures of migration, for domestic, international and pooled labour migrants. Average U.S. migration is significantly higher for the treatment group both at the individual and at the household level. Average U.S. migration is $1.1 \%$ for treatment individuals and $0.7 \%$ for control ones. Hence, program 
availability is associated with a 60 percentage point increase in average migration rate. The proportion of households with at least one international migrant rises from 0.9 to 1.4, corresponding to a 60 percentage point change. However, average household migration does not differ between the two groups.

I interpret this fact as evidence that the program transfers are associated with new households beginning to send their members abroad, rather than households with existing U.S. migrants intensifying their members' migration rates. This may be either because families with pre-program U.S. migrants were either less financially constrained than others to begin with. Alternatively, the presence of migrants and their remittances may loosen the previously existing financial constraints. This may imply that no migrant "rationing" occurred in households with migrants before the program implementation (I abstract from causality issues here). The difference in proportion of households with international migrants persists in 1999. In November 1999 treatment households have a 0.72 percentage point higher likelihood of having at least one U.S. migrant than control households. However, the difference in individual migration rates is no longer statistically significant.

I find the fact that the program may be associated with higher U.S. migration already few months after its beginning very interesting, because very little money had been transferred at that time. The first grants were distributed in May 1998 and, given that there is no schooling in the summer months, the more substantial cash component of the program - the schooling subsidy - is received (for the first or second time) in October-November. The existence of the program and the certainty of eligibility may have loosened financial constraints for poor households also through general equilibrium effects. The link between program availability and loosened financial constraints may operate through two channels: first, the higher liquidity in the communities brought about by the program's cash injection may have increased credit availability. Second, the stream of certain earnings associated with program eligibility may be used as a collateral to borrow. These issues are not further investigated here because they go beyond the scope of the current analysis. However, they clearly deserve more attention. Domestic migration rates do not differ between the control and treatment group. This fact is consistent with domestic migrations being less costly than international ones. Hence, trips within Mexico may be financed more easily than U.S. ones. 
Table 7: 1998 individual migration difference for various household types

\begin{tabular}{ccccccc}
\hline \hline & \multicolumn{3}{c}{ Individual } & \multicolumn{3}{c}{ Household } \\
& migUS & migMX & migALL & migUS & migMX & migALL \\
\hline $\mathrm{TTE}_{g 0}$ & .0004 & -.0001 & .0003 & .0022 & .0029 & .0053 \\
& $(.0008)$ & $(.0025)$ & $(.0030)$ & $(.0018)$ & $. .0040)$ & $. .0047)$ \\
$\mathrm{TTE}_{g 1}$ & $.0010^{*}$ & .0026 & $.0048^{*}$ & $.0039^{* *}$ & -.0045 & .0006 \\
& $(.0006)$ & $(.0025)$ & $(.0028)$ & $(.0019)$ & $(.0049)$ & $(.0053)$ \\
$\mathrm{TTE}_{p 0}$ & .0005 & .0010 & .0016 & .0021 & .0006 & .0030 \\
& $(.0007)$ & $(.0022)$ & $(.0027)$ & $(.0016)$ & $(.0038)$ & $(.0043)$ \\
$\mathrm{TTE}_{p 1}$ & $.0017^{*}$ & .0051 & $.0088^{* *}$ & .0050 & .0032 & .0101 \\
& $(.0009)$ & $(.0036)$ & $(.0039)$ & $(.0029)$ & $(.0067)$ & $(.0073)$ \\
$\mathrm{TTE}_{p 2}$ & .0005 & -.0042 & -.0031 & .0063 & -.0066 & -.0018 \\
& $(.0014)$ & $(.0045)$ & $(.0052)$ & $(.0044)$ & $(.0092)$ & $(.0102)$ \\
\hline \hline
\end{tabular}

Standard errors clustered at the village level. Tests of the IIA assumption show that odds are independent of other alternatives.

Table 8: 1999 migration difference for various household types

\begin{tabular}{lcccccc}
\hline \hline & \multicolumn{3}{c}{ Individual } & \multicolumn{3}{c}{ Household } \\
& migUS & migMX & migALL & migUS & migMX & migALL \\
\hline $\mathrm{TTE}_{g 0}$ & -.0008 & $-.0030^{*}$ & -.0048 & -.0018 & $-.0046^{* *}$ & $-.0074^{* * *}$ \\
& $(.0010)$ & $(.0018)$ & $(.0027)$ & $.0017)$ & $(.0022)$ & $(.0031)$ \\
$\mathrm{TTE}_{g 1}$ & .0004 & .0003 & .0011 & -.0010 & .0016 & .0002 \\
& $(.0008)$ & $(.0015)$ & $(.0021)$ & $(.0015)$ & $(.0020)$ & $(.0026)$ \\
$\mathrm{TTE}_{p 0}$ & .0006 & -.0022 & -.0017 & -.0007 & -.0010 & -.0022 \\
& $.0008)$ & $(.0016)$ & $(.0022)$ & $(.0013)$ & $(.0019)$ & $(.0025)$ \\
$\mathrm{TTE}_{p 1}$ & -.0013 & .0027 & .0014 & -.0026 & -.0003 & -.0016 \\
& $. .0011)$ & $(.0024)$ & $(.0031)$ & $(.0037)$ & $(.0033)$ & $(.0044)$ \\
$\mathrm{TTE}_{p 2}$ & -.0014 & -.0016 & -.0041 & -.0032 & -.0062 & $-.0123^{* *}$ \\
& $. .0013)$ & $(.0030)$ & $(.0038)$ & $(.0048)$ & $(.0049)$ & $(.0062)$ \\
\hline \hline
\end{tabular}

Standard errors clustered at the village level. Tests of the IIA assumption show that odds are independent of other alternatives. 


\subsection{Heterogeneous treatment effects}

Tables 7 and 8 present the TTEs for households with similar size and type of offspring obtained from (6). In this way, one can observe which group is affected by the program.

This exercise reveals that in 1998 treated households with above average grant amount are significantly more likely to have U.S. migrants than similar families in the control group. Further investigation reveals that, although all large transfer recipients have higher migration rates than the control group, the difference is particularly marked among households with a low to medium proportion of conditional grant (i.e. those with $p=1$ ). One possible interpretation of these results, consistent with the credit constraint hypothesis, is that families entitled to sufficiently large transfers may use them to fund international trips either directly or as collateral to borrow against (hence the absence of treatment effects for low grant sizes). However, this does not happen when subsidies are linked to the home stay of potential migrants (hence the absence of treatment effect for recipients of large grants due mainly to secondary scholarships). Since the evidence in Table 7 is insufficient to disentangle the two effects, I will return to this point when commenting the next set of estimated parameters.

Whichever the driving force behind the significant differences in 1998, they disappear in 1999. According to Table 8, in fact, not only large grant recipients stop having different migration rates than control individuals. Also, recipients of low levels subsidies present a significantly lower rate of domestic migration. The next sets of results will shed more light on this issue. To conclude, note that the significant negative sign of $T T E_{p 2}$ is consistent with the predicted conditionality effect.

I now proceed to assess the impact of the two program components - conditional and unconditional transfers. I test their impact by regressing the individual and household migration likelihood on controls for potential household grant size and its proportion due to male secondary school attendance, as in (8).

Table 9 presents the estimates of the parameters of interest when I consider the variables as first- and second-order polynomials, alternatively. The coefficients from the linear specification for both domestic and international migration are not statistically significant. The quadratic specification instead reveals that U.S. migration among the treated group is a positive function of grant composition, for households where less than one third of the transfer is linked to male secondary school attendance (for whom the individual foreign migration likelihood is 0.2 percentage point higher than the control group). Beyond that 
Table 9: Marginal effects of program components - individual-level 1998 data

\begin{tabular}{ccccccc}
\hline \hline & \multicolumn{5}{c}{$(1)$} & \multicolumn{2}{c}{$(2)$} & $(3)$ & $(4)$ \\
& \multicolumn{5}{c}{ Multinomial logit } & \multicolumn{2}{c}{ Logit } \\
\hline treatment dummy & .0009 & .0000 & .0011 & .0002 & $.0043^{*}$ & .0062 \\
& $(.0009)$ & $(.0036)$ & $(.0017)$ & $(.0054)$ & $(.0025)$ & $(.0040)$ \\
proportionSM & .0017 & -.0054 & $.0163^{* *}$ & .0298 & -.0012 & .0182 \\
& $(.0019)$ & $(.0064)$ & $(.0086)$ & $(.0227)$ & $(.0054)$ & $(.0170)$ \\
proportionSM & & & $-.0243^{*}$ & $-.0564^{*}$ & & .0314 \\
& & & $(.0138)$ & $(.0337)$ & & $(.0264)$ \\
hh grant $\left({\left.\mathrm{x} 10^{4}\right)}\right.$ & -.0079 & .0303 & -.0107 & .0345 & -.0401 & -.1130 \\
& $(.0118)$ & $(.0419)$ & $(.0126)$ & $(.0521)$ & $(.0392)$ & $(.1472)$ \\
hh grant $^{2}\left({\left.\mathrm{x} 10^{4}\right)}\right.$ & & & -.0564 & -.1810 & & .4290 \\
& & & $(.0692)$ & $(.2038)$ & & $(.6731)$ \\
\hline \hline
\end{tabular}

The above continuous variables have been interacted by the treatment dummy. Standard errors clustered at the village level. Tests of the IIA assumption show that odds are independent of other alternatives.

value the relationship is inverted: the higher the proportion of the grant due to male secondary scholarships in the household, the lower the likelihood of being an international migrant. People from families with the highest proportion of conditional grant are 0.3 percentage points less likely to be abroad. A possible explanation for this specific functional form may be that the grant income effect dominates the composition one initially because the money is mainly transferred unconditionally. When the proportion of conditional grant increases, households shift their offspring's time allocation from migration to schooling.

The likelihood of being a domestic migrant decreases more than proportionally as the proportion of conditional grant goes up. From Table 9, individuals in households with maximum conditional grant are 4 percentage points less likely to migrate than those in families with no eligible secondary school males. Analysis at the household levels reveals that Mexican migration is also a negative function of grant size: 100 extra pesos decrease migration by 0.16 percentage points. However, most eligible households have higher domestic migration rates than control ones, as shown by the significance of the treatment dummy coefficient. Only households with a potential grant size exceeding 630 bimonthly pesos have an overall decrease in Mexican migration. 
Table 10: Marginal effects of program components - household-level 1998 data

\begin{tabular}{|c|c|c|c|c|c|c|}
\hline & \multicolumn{2}{|c|}{ (1) } & \multicolumn{2}{|c|}{$(2)$} & (3) & (4) \\
\hline & \multicolumn{4}{|c|}{ Bivariate Probit $^{a}$} & \multicolumn{2}{|c|}{ Probit } \\
\hline & migUS & $\operatorname{migMX}$ & migUS & migMX & migALL & migALL \\
\hline \multirow[t]{2}{*}{ treatment dummy } & -.0031 & $.0106^{* *}$ & .0037 & .0107 & .0074 & .0138 \\
\hline & $(.0039)$ & $(.0051)$ & $(.0067)$ & $(.0087)$ & $(.01354)$ & $(.2448)$ \\
\hline \multirow[t]{2}{*}{ proportionSM } & -.0003 & .0196 & .0085 & .0586 & .0193 & .0750 \\
\hline & $(.0088)$ & $(.0152)$ & $(.0266)$ & $(.0389)$ & $(.0179)$ & $(.0489)$ \\
\hline \multirow[t]{2}{*}{ proportionSM $^{2}$} & & & -.0138 & -.0631 & & -.0895 \\
\hline & & & $(.0393)$ & $(.0567)$ & & $(.0713)$ \\
\hline \multirow[t]{2}{*}{ hh grant $\left(x 10^{4}\right)$} & $.1080^{*}$ & $-.1680^{* *}$ & -.1883 & -.1599 & -.0457 & -.3268 \\
\hline & $(.0574)$ & $(.0857)$ & $(.2811)$ & $(.3634)$ & $(.1038)$ & $(.4668)$ \\
\hline \multirow[t]{2}{*}{ hh $\operatorname{grant}^{2}\left(\mathrm{x} 10^{4}\right)$} & & & $.2253^{*}$ & -.1997 & & 1.9159 \\
\hline & & & $(.1357)$ & $(.8528)$ & & $(3.3612)$ \\
\hline
\end{tabular}

The above continuous variables have been interacted by the treatment dummy. Standard errors clustered at the village level. ${ }^{a}$ : rho is positive and significant.

Household-based data analysis also reveals a pattern broadly consistent with the predictions of the model, although not necessarily with the evidence from individual-level data. Bivariate probit estimates show a positive correlation between grant size and international migration. The coefficient from the first column of Table 10 implies that 100 extra pesos increase the likelihood of having international migrants in the treated group by 0.1 percentage points (corresponding to a $7 \%$ increase at mean values). The effect is even smaller when using the result from the quadratic specification.

To sum up, the results from 1998 show that Progresa is associated with an increase in international migration coupled with a reduction in domestic ones, to some extent. Both pieces of evidence are consistent with the view that credit constraints may influence the household migration decisions. As not all desired international migrations can be financed, some members will be allocated to domestic migration. The size of the effects is small, though. A possible explanation may be the recent implementation of the program: in November 1998, households had been receiving schooling grants (which constitute the bulk of the financial assistance) only once or perhaps twice. The little money actually received may limit their scope for changes in migration intensity and destination.

The magnitude of the effect in 1999 does not appear to be larger, though, at least for 
Table 11: Marginal effects of program components - individual-level 1999 data

\begin{tabular}{|c|c|c|c|c|c|c|}
\hline & ( & & & 2) & (3) & (4) \\
\hline & \multicolumn{4}{|c|}{ Multinomial logit } & \multicolumn{2}{|c|}{ Logit } \\
\hline & migUS & migMX & migUS & migMX & migALL & $\operatorname{mig} A L L$ \\
\hline \multirow[t]{2}{*}{ treatment dummy } & -.0003 & -.0015 & -.0015 & .0016 & $-.0062^{*}$ & .0001 \\
\hline & $(.0014)$ & $(.0025)$ & $(.0026)$ & $(.0039)$ & $(.0039)$ & $(.0071)$ \\
\hline \multirow[t]{2}{*}{ proportionSM } & $-.0046^{* *}$ & .0036 & -.0083 & $.0320^{* *}$ & -.0022 & .0363 \\
\hline & $(.0023)$ & $(.0047)$ & $(.0065)$ & $(.0152)$ & $(.0071)$ & $(.0235)$ \\
\hline \multirow[t]{2}{*}{ proportionSM ${ }^{2}$} & & & .0049 & $-.0454^{*}$ & & -.0601 \\
\hline & & & $(.0081)$ & $(.0239)$ & & $(.0308)$ \\
\hline \multirow[t]{2}{*}{ hh grant $\left(x 10^{4}\right)$} & .0179 & -.0010 & .0641 & $-.2486^{* *}$ & $.0663^{*}$ & -.0347 \\
\hline & $(.0185)$ & $(.0333)$ & $(.0745)$ & $(.1268)$ & $(.0408)$ & $(.3154)$ \\
\hline \multirow[t]{2}{*}{ hh $\operatorname{grant}^{2}\left(\mathrm{x} 10^{4}\right)$} & & & .3257 & $1.6083^{*}$ & & $1.8204^{*}$ \\
\hline & & & $(.7754)$ & $(.9162)$ & & (1.0002) \\
\hline
\end{tabular}

The above continuous variables have been interacted by the treatment dummy. Standard errors clustered at the village level. Tests of the IIA assumption show that odds are independent of other alternatives.

international migration. The individual likelihood of being in the US is 0.23 percentage point lower for those in families where half of the grant is due to male secondary scholarship, and 0.38 percentage point lower for households with the maximum proportion of conditional grant. Moreover, the evidence from Table 11 (columns 2 and 4) is to some extent puzzling: for households with conditional transfers exceeding one third of the total, a higher proportion of conditional grant increases the likelihood of having one or more foreign migrants. This issue will be further investigated below. There is also a negative relationship between grant size and U.S. migration, for low potential grant levels. The relation is instead positive for bimonthly subsidies larger than 660 pesos and positive for low conditional grant proportions.

The effect of the program component on domestic migration is similar in sign and magnitude to the 1998 one. There are negative grant composition and size effects, both at the individual and at the household level (the quadratic grant function in Table 12, column 2 has a negative first derivative throughout its support). As in 1998, the reduction in Mexican migrations for beneficiaries of large grants is more than compensated by an increase in U.S. trips, resulting in an overall positive relationship between subsidy size and individual migration (Table 12, columns 3 and 4). 
Table 12: Marginal effects of program components - household-level 1999 data

\begin{tabular}{|c|c|c|c|c|c|c|}
\hline & \multicolumn{2}{|c|}{ (1) } & \multicolumn{2}{|c|}{$(2)$} & (3) & (4) \\
\hline & \multicolumn{4}{|c|}{ Bivariate Probit $^{a}$} & \multicolumn{2}{|c|}{ Probit } \\
\hline & migUS & $\operatorname{migMX}$ & migUS & $\operatorname{migMX}$ & migALL & migALL \\
\hline \multirow[t]{2}{*}{ treatment dummy } & -.0012 & .0048 & .0044 & -.0057 & .0035 & -.0006 \\
\hline & $(.0046)$ & $(.0055)$ & $(.0084)$ & $(.0123)$ & $(.1375)$ & $(.2790)$ \\
\hline \multirow[t]{2}{*}{ proportionSM } & -.0016 & -.0093 & $-.0559^{* *}$ & .0653 & -.0101 & .0045 \\
\hline & $(.0033)$ & $(.0124)$ & $(.0299)$ & $(.0402)$ & $(.0147)$ & $(.0489)$ \\
\hline \multirow[t]{2}{*}{ proportionSM $^{2}$} & & & $.0881^{* *}$ & $-.1082^{*}$ & & -.0223 \\
\hline & & & $(.0471)$ & $(.0605)$ & & $(.0732)$ \\
\hline \multirow[t]{2}{*}{ hh grant $\left(\mathrm{x} 10^{4}\right)$} & .0776 & -.0191 & $-.4910^{*}$ & .4137 & .0712 & .2416 \\
\hline & $(.0448)$ & $(.0734)$ & $(.2974)$ & $(.4401)$ & $(.1031)$ & $(.5752)$ \\
\hline \multirow[t]{2}{*}{ hh $\operatorname{grant}^{2}\left(\mathrm{x} 10^{8}\right)$} & & & $3.6808^{* *}$ & -3.4938 & & -.0922 \\
\hline & & & $(1.8402)$ & $(4.5971)$ & & $(.3546)$ \\
\hline
\end{tabular}

The above continuous variables have been interacted by the treatment dummy. Standard errors clustered at the village level. ${ }^{a}$ : rho is positive and significant.

To conclude, the evidence provided so far is consistent with the picture emerged from the theoretical model: increasing the income of financially constrained household may result in an increase of costly migration, which could not be funded before. This is shown both directly (significantly larger number of U.S. migrants) and indirectly (through the possible substitution of domestic for international trips). The magnitude of these effects appears to be quite small.

The current analysis presents two main shortcomings: first, it is hard to reconcile the positive relationship between the composition effect and 1999 household U.S. migration with the theoretical predictions. Second, the two program components are never jointly significant in a single specification. This might be caused by the limited variation in the data caused by the few observed migrations. In order to test for the joint significance of the effect, and to test for the robustness of the results, I relax the functional form assumption and proceed with the estimation of cell means, as explained above.

The TTEs presented in Tables 13 and 14 are estimated from (univariate or bivariate) probits of the likelihood of being a migrant, or of having migrants in the household, interacting the treatment dummy by the discrete variables grouping grant level and composition, as described above. The estimated effects suggest that both domestic and U.S. 
Table 13: Marginal effects of program components - 1998

\begin{tabular}{|c|c|c|c|c|c|c|}
\hline & \multicolumn{3}{|c|}{ (1) } & \multicolumn{3}{|c|}{ (2) } \\
\hline & \multicolumn{6}{|c|}{1998} \\
\hline & \multicolumn{3}{|c|}{ Individual-level data } & \multicolumn{3}{|c|}{ Household-level data } \\
\hline & migUS & migMX & migALL & migUS & migMX & migALL \\
\hline \multirow[t]{2}{*}{$T T E_{g 10}$} & .0000 & .0027 & .0033 & $.0124^{* *}$ & $-.0088^{* *}$ & -.0009 \\
\hline & $(.0012)$ & $(.0038)$ & $(.0044)$ & $(.0077)$ & $(.0044)$ & $(.0076)$ \\
\hline \multirow[t]{2}{*}{$T T E_{p 10}$} & .0015 & .0024 & .0055 & .0025 & .0174 & .0205 \\
\hline & $(.0021)$ & $(.0052)$ & $(.0062)$ & $(.0079)$ & $(.0158)$ & $(.0174)$ \\
\hline \multirow[t]{2}{*}{$T T E_{p 20}$} & .0000 & -.0054 & -.0054 & -.0020 & .0085 & .0054 \\
\hline & $(.0016)$ & $(.0032)$ & $(.0041)$ & $(.0047)$ & $(.0134)$ & $(.0132)$ \\
\hline \multirow[t]{2}{*}{$T T E_{p 21}$} & -.0010 & -.0071 & $-.0093^{*}$ & -.0036 & -.0047 & -.0091 \\
\hline & $(.0012)$ & $(.0038)$ & $(.0045)$ & $(.0046)$ & $(.0069)$ & $(.0083)$ \\
\hline
\end{tabular}

Tests of the IIA assumption show that odds are independent of other alternatives. The correlation between the residuals from the household-level estimation is positive and significant. Standard errors clustered at the village level. Regression estimates available upon request.

migrations are a function of grant size and composition. The effects tend to be more marked in 1999, when more money has been distributed and households have had enough time to respond to the new set of incentives.

As regards international migration, the effect of the program on migration is larger for high grant sizes, i.e. the likelihood of having migrants in the household is a positive function of transferred resources. A household that receives a high grant level is (in 1998 and 1999, respectively) 1.2 and 2.4 percentage points more likely to have at least one US migrant member than one that receives a low grant level (when both are compared with the respective control group). The same applies to individual data in 1999. This is consistent with the credit constraint hypothesis.

Conditioning the grant to secondary school attendance reduces contemporaneous U.S. migration. In 1999, individuals from households with at least one secondary school eligible male are 0.2 percentage point less likely to be U.S. migrants than those in households where all transfers are unconditional. However, households with a high proportion of conditional transfers are more likely to have spells of U.S. migration than those with low to medium conditional grants. A similar conclusion had been reached when imposing explicit functional forms. A possible explanation of this migration pattern will be pursued 
Table 14: Marginal effects of program components - 1999

\begin{tabular}{|c|c|c|c|c|c|c|}
\hline & \multicolumn{3}{|c|}{ (3) } & \multicolumn{3}{|c|}{ (4) } \\
\hline & \multicolumn{6}{|c|}{1999} \\
\hline & \multicolumn{3}{|c|}{ Individual-level data } & \multicolumn{3}{|c|}{ Household-level data } \\
\hline & migUS & migMX & migALL & migUS & migMX & migALL \\
\hline \multirow{2}{*}{$T T E_{g 10}$} & $.0039^{* *}$ & .0020 & $.0073^{*}$ & $.0243^{* * *}$ & $-.0096^{*}$ & .0030 \\
\hline & $(.0023)$ & $(.0026)$ & $(.0043)$ & $(.0103)$ & $(.0046)$ & $(.0088)$ \\
\hline \multirow[t]{2}{*}{$T T E_{p 10}$} & $-.0023^{* * *}$ & .0045 & -.0010 & $-.0086^{* * *}$ & .0155 & -.0015 \\
\hline & $(.0006)$ & $(.0045)$ & $(.0042)$ & $(.0020)$ & $(.0157)$ & $(.0109)$ \\
\hline \multirow[t]{2}{*}{$T T E_{p 20}$} & $-.0020^{* * *}$ & -.0000 & -.0042 & -.0000 & -.0046 & -.0030 \\
\hline & $(.0005)$ & $(.0032)$ & $(.0031)$ & $(.0053)$ & $(.0055)$ & $(.0084)$ \\
\hline \multirow[t]{2}{*}{$T T E_{p 21}$} & .0006 & -.0033 & -.0034 & $.0248^{*}$ & $-.0112^{* *}$ & -.0016 \\
\hline & $(.0016)$ & $(.0026)$ & $(.0037)$ & $(.0204)$ & $(.0039)$ & $(.0116)$ \\
\hline
\end{tabular}

Tests of the IIA assumption show that odds are independent of other alternatives. The correlation between the residuals from the household-level estimation is positive and significant. Standard errors clustered at the village level. Regression estimates available upon request.

below.

The relationship between domestic migration and grant size is negative. This fact may be interpreted in two different ways. Households may be shifting migrants from Mexico to the US, as they are able to fund the more expensive, yet potentially more rewarding international trips. Alternatively, this result may be evidence of the "home bias" effect: the additional income received through Progresa makes migration more costly (for instance because of the higher level of forgone home consumption), resulting in fewer members being away. The first interpretation seems more sensible. If the "home bias" effect were the dominating one, there would not be a surge in international migration.

As far as the conditionality effect is concerned, there is evidence that higher proportions of conditional grants are associated with lower migration rates also for Mexican migration in 1999.

To test the robustness of the result, I tried to condition on different sets of households. Moreover, I included measures of the conditional grant proportion associated with female secondary scholarships. The results did not change in either case. 


\subsubsection{Effect of a cap on maximum transfer size on international migration}

The previous analysis has revealed that households with a high proportion of conditional transfers are more likely to have spells of U.S. migration in 1999 than those with low to medium conditional grants. Here I check whether this may be caused by the subsidy cap. The maximum bimonthly amount that households are entitled to is 1170 pesos in November 1998, and 1390 the following year. Households with a number of eligible children that exceeds the maximum subsidy have the individual school grants re-scaled to sum up to the maximum level. Hence, their monetary incentives to send members to school are lower, and the comparative incentives for migration higher. Visual observation of cell means confirms this intuition: mean U.S. migration for treated households - but not for control ones - decreases when capped households are excluded from the computation both in 1998 and 1999.

To test this hypothesis, I first interact the treatment dummy with a variable taking the value of one for those households that are capped because they have an "excess" of secondary school males. I repeat the same exercise with a dummy for all "capped" households, irrespective of their school children composition. The magnitude and significance of the estimated TTEs do not change in either occasion, though.

However, when I create a third grant size category to group capped households (hence the new $g$ takes three values, 0 , for up to medium potential grant size, 1 , for higher than average grant size, 2, for maximum grant size and an "excess supply" of eligible school children), the significance of $T T E_{p 21}$ becomes much weaker (with a $\mathrm{p}$ value of .133), and its magnitude slightly smaller, dropping to 1.9. This only holds when considering the households with "too many" eligible secondary school males, and not with all capped households. I interpret this fact as evidence that the presence of a cap on the maximum size of the transfer may increase migration (although other factors may be present too). This result confirms once more how the different modes and formats of aid to developing countries may have different impacts on household time allocation, even when the same amount of money is being transferred.

\subsection{Medium-term migration}

So far I have shown that Progresa is associated with a short-term increase in average international migration. I have inferred that this is due primarily to the existence of an unconditional transfer component, i.e. that households are transferred money without 
having to comply with requirements that force them not to migrate. However, I have also shown that conditional transfers targeting prospective migrants may achieve a migration reduction in the short run. In fact, households with a sufficiently high proportions of secondary school males may end up having lower migration rates than before the program implementation because of its "conditionality" effect (i.e. the necessity to comply with the program requirements in order to be eligible for the subsidy). However, it is possible that secondary school males may revert to migration after they complete secondary education. The model shows that their future choices depend on the location where their accumulated human capital reaps the highest return - and that such location may not necessarily be abroad, but rather in Mexican urban centres such as state capital.

One way to assess the medium-term program effect on migration is to look at choices of individuals who have completed the first three years of secondary school. I focus on the sub-set of individuals aged 15 to 18 with some or complete junior high-school education in November 1999. These individuals were potentially entitled to the program educational grant for the 1998-1999 academic year. I then look at whether children from treatment villages are significantly more likely to migrate than children from the control group.

I create two dichotomous variables that record migrations for two categories of teenagers: those with complete junior high school in 1999, and those with some level of secondary education. I focus on trips started in the six months between the end of the academic year, which I assume to be at the beginning of June, and the interview time, in November. The valid sample consists of 1567 individuals with completed junior high school, and of 3602 ones with at least one year of secondary education.

Table 15: Average migration rate of 1999 secondary schoolchildren

\begin{tabular}{lll}
\hline \hline Sub-sample & Complete junior high & $\geq 1$ year secondary education \\
\hline Treatment & .024 & .013 \\
& $(.007)$ & $(.003)$ \\
Control & .023 & .014 \\
& $(.006)$ & $(.004)$ \\
\hline p-value of difference & .933 & .776 \\
\hline \hline
\end{tabular}

Standard errors clustered at the village level.

Mean comparison of the individual likelihood of undertaking a migration shows that children from treatment localities do not have different migration propensities than those 
in control ones. Although the size of the sample is quite small, and the fact they do not migrate immediately after the end of the transfer does not prevent them from undertaking future migration, this result suggest that education support programs may not cause higher migration in the medium term.

One shortcoming of the current analysis is that ideally one would want to observe post-schooling migration behaviour of individuals who began to go to junior high school because of the program implementation, rather than those who took advantage of the scholarship while they had already started the schooling cycle. Unfortunately, the first such cohort graduates in 2001. In 1999 only the latter group is observed. More research is needed in this field.

\section{Conclusions}

The current exercise contributes to our knowledge of the relationship between aid and migration by analysing the impact of the development program Progresa on domestic and international migration of poor rural households. In particular, I have tried to understand how different program components may provide opposite incentives to migrate. The theoretical model has shown that unconditional transfers may increase migration rates by loosening the credit constraints faced by indigent households. The larger the poverty level, the higher the likelihood that this effect dominates any (supposed) "home bias", often described in the literature as a preference for home consumption. Conditional transfers that target potential migrants and require them to stay at home are associated with a migration reduction in the short run. Individual behaviour in the medium run and their migration choices depend on differentials in returns to the extra skills learned.

The empirical analysis, which considers migrations both as an individual and as a household decision, uncovers interesting facts. First, the program is associated with an increase in average international migration, confirming that fact that credit-constrained households may be forced to undertake a sub-optimal number of potentially profitable migrations because of the impossibility to finance the trips. Second, the extra cash is used to finance migrations in households who did not have any migrant previously, rather than increase average migration rates for all households. Third, average domestic migration levels are not affected by program availability, suggesting that it is mainly the more costly international trips that cannot be financed by poor households.

Fourth, the existence of the program may increase the level of borrowing among poor 
households, by injecting cash in the villages or by being used as a collateral to access the credit market. This is deduced by observing that international migration rates increase after very little money is transferred to households, and do not grow in a way correlated with the total amount of cash transferred over time (i.e. total program effect does not differ substantially for treatment poor between November 1998 and November 1999).

Fifth, different households face varying migration incentives linked to their demographic composition. Those with a large grant proportion coming from secondary school subsidies will migrate less than those for whom the program requirements are not binding (i.e. families with primary school children). One exception to this pattern is provided by 1999 U.S. trips (when modelled as decided at the household level, rather than at the individual one), which appear to be higher for high than for medium conditional grant proportions. A partial explanation is given by showing that households where not all secondary school males are entitled to the school subsidy because of a cap on the maximum grant size are more likely to have U.S. migrants. However, additional (and yet uncovered) factors are likely to play a significant role in explaining this puzzling effect.

Sixth, as (potential) grant size increases, households substitute (cheaper but with lower return) domestic for (costlier but with a higher benefit) international migration. This fact provides additional evidence of the importance of credit constraints in developing countries. Nevertheless, the net creation of migration associated with Progresa is positive.

Seventh, the secondary school subsidy is not associated with a post-program increase in migration. I observed the location choice of teenagers with completed junior high school in 1999. There is no significant post-program different migration rate between individuals from treatment and control groups.

These findings have interesting policy implications. They show that it is possible to implement aid policies that do not result into higher international migration. The way to insure that the transfers are used to finance extra migrations is to give emphasis to conditional grants such as subsidies for secondary education. This approach is already being pursued, albeit perhaps unintentionally. In fact, Progresa has been recently extended to cover Mexico's urban areas (under the name of Oportunidades). There, the education transfer has been extended in order to subsidize also additional schooling years. It is possible that this type of transfer may result into a net reduction in short-term international migration. If skilled wages in urban Mexico are sufficiently high, the program may not even cause higher medium-term U.S. migration.

The current research has also pointed out directions for further investigation. One 
is to understand the effect of the program on access to credit. The other is to look at comparative effects of different policies on international migration, such as aid and border enforcement.

\section{Bibliography}

1. Albarran, P. and Attanasio, O. (2002), "Do public transfers crowd out private transfers? Evidence from a randomized experiment in Mexico", DP2002/06, World Institute for Development Economics Research.

2. Attanasio, O., Meghir, C. and Santiago, A. (2001), "Education choices in Mexico: using a structural model and a randomized experiment to evaluate Progresa", EDePo EWP04/04, Centre for the Evaluation of Development Policies, IFS.

3. Behrman, J.R. and Todd, P. (1999), "Randomness in the experimental samples of Progresa (education, health and nutrition program)", mimeo, International Food Policy Research Institute.

4. Djajic, S. and Milbourne, A. (1988), "A general equilibrium model of guest-worker migration", Journal of International Economics, 25, 335-51.

5. Dubois, P., de Janvry, A. and Sadoulet, E. (2001), "Effects on school enrollment and performance of a conditional transfers program in Mexico", mimeo.

6. Faini, R. and Venturini, A. (1993), "Trade, aid and migrations. Some basic policy issues", European Economic Review, 37, 435-442.

7. Faini, R. and Venturini, A. (1994), "Migration and growth: the experience of Southern Europe", CEPR Discussion Paper 964.

8. Faini, R. and Venturini, A. (2001), "Home bias and migration: why is migration playing a marginal role in the globalization process?", CHILD Working Paper 27/2001.

9. Katz, E. and R. and Stark, O. (1986), "Labour migration and risk aversion in less developed countries", Journal of Labour Economics, 4(1), 134-49.

10. Schultz, T. P. (2004), "School subsidies for the poor: evaluating the Mexican PROGRESA poverty program", Journal of Development Economics, 74(1), 199-250. 
11. Skoufias, E., Davies, B and Behrman, J.R. (1999), "Final report - An evaluation of the selection of beneficiary households in the education, health and nutrition program (PROGRESA) of Mexico", mimeo, International Food Policy Research Institute.

12. Skoufias, E., Davies, B and de la Vega, S. (1999), "Targeting the poor in Mexico: an evaluation of the selection of households into PROGRESA ", mimeo, International Food Policy Research Institute.

13. Stark, O. and Taylor, J. E. (1991), "Migration incentives, migration types: the role of relative deprivation", Economic Journal, 101, 1163-78.

14. Steckov, G., Winters, P., Stampini, M. and Davis, B. (2003), "Can public transfers reduce Mexican migration? A study based on randomized experimental data", ESA WP 03-16, Food and Agriculture Organisation.

\section{Appendix: variables creation}

In this section, further information is provided on the creation of the variables of interest, potential grant size and composition.

No information is available on effective size of the received transfer. Hence, it is only possible to compute the potential transfer size. This approach rules out endogeneity issues related to partial acceptance of the program, while it permits the estimation of parameters with strong policy relevance: the impact of the availability of a transfer (the policy maker cannot force individuals to comply with the program requirements). Its drawback is the difficulty of assessing the effective monetary impact of the program.

Potential grant size is computed considering all children aged 5 to $18^{19}$ in the November 1998 survey using last completed school grade. I use 1998 information rather than 1997 one because I would like to include current migrants in the computed potential grant, given that some of them, especially those who are in the same state, may actually decide to go back to school. No information on schooling level of migrants is available in the September 1997 survey. A consequence of this choice is that there will be differences in 1999 potential grant size estimated using 1997 versus 1998 data. In the latter case, only children who completed the first year of primary school in the 1997-1998 academic

\footnotetext{
${ }^{19} 18$ year old individuals are dropped from the computation in 1999. Children aged 5 in November 1998 are included in case they reach third grade in the 1999-2000 academic year.
} 
year will be considered eligible for the program in the academic year 1999-2000 (having assumed that they completed their second grade in 1998-1999). Potential grant size built projecting grade completion information for the 1996-1997 academic year, instead, must assume that all children aged 6 in September 1997 will have completed second grade by June 1999. Only if I match grade completion data with current enrolment for first-graders will the two measures coincide in 1999. A further difference is given by the fact that using 1998 information I do not have to assume that nobody fails in the 1997-1998 academic year.

Two implicit assumptions are made in the computation of potential grant size: first, grade completion is independent from existence of the program. The assumption is violated if the latter is a function of future program eligibility. Children progressing to a subsidized grade may have higher incentives to pass, while those in the final subsidized grade may be more likely to fail to receive benefits the following year. Second, it is assumed that all students pass the grade, independently of actual school attendance and of whether the child actually left the household. Again, any strategic behaviour has been hence ruled out.

Four measures of potential grant amount are built and used in the estimations. Such measures are obtained by varying two parameters: the type of children included and the time dimension considered. As regards the former, in one case only November 1998 residents are included in the computation, hence omitting all children who are elsewhere for any sort of reason. The time dimension varies in the sense that in one case I estimate current bimonthly transfer size computed for both November 1998 and November 1999, while in another case I compute total potential amount. In this way, emphasis is given to the fact that the cumulative grant, rather than the current one, matters for financially constrained households. There is some variation among the two only in 1999, given by families with children in the third year of junior high in the 1998-1999 academic year.

The figures shown below are computed excluding migrants. Moreover, for 1999 data, they only use the estimated value of potential current grant, instead of using the cumulative one. However, the results are robust to the use of the alternative measures of potential grant and its composition.

Identification of the parameters of interest in the assessment of the effect of the program components is possible for the following reasons. First, the number and composition of eligible schoolchildren by households is very similar among control and treatment villages and it insures that potential grant size has a common support for the two groups. I created 
Table 16: Average pre-program potential grant size (at 1999 values) and grant composition

\begin{tabular}{lll}
\hline \hline Variable & Grant size & Composition $^{a}$ \\
\hline Treatment & 560 & .055 \\
& $(8.2)$ & $(.003)$ \\
Control & 562 & .050 \\
& $(10.3)$ & $(.003)$ \\
\hline p-value of difference & 0.906 & 0.286 \\
\hline \hline
\end{tabular}

${ }^{a}$ : grant composition measured as proportion of grant due to male secondary school attendance.

Standard errors clustered at the village level.

potential grant size and grant composition measures also for the 1997 sample, using 1999 grant size. ${ }^{20}$ There is no significant difference for both potential grant size and grant composition between control and treatment households. Second, there is a large variation in the number, gender and school level of eligible children by family also within treated households. Indeed the correlation between grant size and composition is positive and significant, amounting to 0.47 (0.46 for treatment poor only) in 1997, but it is far from one. Third, the specific grant amounts are such that different combinations of primary and secondary school beneficiaries yield the same potential transfer level. Hence, households entitled to roughly equivalent grant levels may vary substantially in the proportion of secondary school males.

\footnotetext{
${ }^{20}$ I.e. the size and composition of grant that one household would be entitled to in 1997 , had the program been already implemented with 1999 scholarship levels.
} 